\title{
DIVERSIFICATION AS A TOOL OF ANTI-CRISIS STRATEGY OF DEVELOPMENT OF RURAL TERRITORIES IN UKRAINE
}

\author{
Arthur ILNITSKY ${ }^{1}$, Alla CHIKUROVA ${ }^{2}$, \\ Podolsky State Agrarian Technical University, Ukraine
}

\begin{abstract}
The main goal of this work is to study the problems of rural development in a crisis situation and shows one of the outputs of the socio-economic problems of rural development, namely the proposed diversification of production and services. Because increased competition in the market requires a search for new effective ways and methods to ensure the survival of enterprises in rural areas in a market environment. One of these methods is the introduction of diversification. Diversity own economic and financial activity of various branches in rural areas is carried out not only in the context of globalization of the world economy associated with the interpenetration of capital and technology, but also in times of crisis as a tool of anti-crisis strategy. The effectiveness of its implementation depends on the timely focus on the types of goods and services that are in demand or close to the level of competitiveness. The question of the development strategy involving the development of methods of receiving, processing and communication of information related to the development of new technologies, products, markets and other areas and activities, as well as identify patterns to determine the motivation of diversification as a development strategy in rural areas. The methodological basis for the development of this paper, aimed at the development of rural areas in all its multidimensionality become fundamental research and active discussions among qualified experts and stakeholders, and formed on their basis of decisions of state and local governments targeted the development of production capacity, improve the quality of the environment and improving the quality of human capital in rural areas of Ukraine. Result. Diversification of economic activities in the rural development is not only adequate response to the challenges of a globalizing world economy associated with the interpenetration of capital and technology, but also in times of crisis - is one of the tools of anti-crisis strategy. The effectiveness of diversification depends on timely guidance on the types of goods and services that are in demand or close to the level of competitiveness. The practical value. Thus, our proposed mechanism for developing a program of social development will help meet the needs of the population in social infrastructure, solve the problem of territorial distribution of these facilities, to develop concrete measures to improve the functioning of the social infrastructure for various purposes and most importantly - to find ways financing of such programs will allow overcoming disparities of regions of Ukraine in general and the regions and districts to provide people with jobs. Value/originality. Diversification of the rural economy is the key to a significant decrease dependence on agriculture and the development of new economic activities, creating new businesses and investments. It can also help increase employment and income of rural population increased output of high value added, improving the quality of human capital and, finally, help boost rural development.
\end{abstract}

Key words: diversification of the rural strategy, rural economy, rural tourism, the problems of development of rural territories.

JEL Classification: J16, O1, 013, 018

\section{1. Введение}

Современные тенденции развития сельских территорий Украины происходят в направлении сужения сферы приложения труАа и несоответствия профессионально-квалифицированной качестве рабочих потребностям работодателей, рост безработицы. Проблема Аиверсификации сфер занятости сельских жителей осо- бенно актуальна в регионах Украины с высокой Аолей крестьян.

Особую актуальность развитие предпринимательства приобретает в сельской местности Украины. Поскольку село - это не только место проживания значительной части гражАан, но и среАу их социального и культурного развития, места работы, быта и т. Невоз-

Corresponding author:

${ }^{1}$ Department of Management of Organizations and Administration, Podolsky State Agrarian Technical University.

E-mail: g-unit120590@mail.ru

${ }^{2}$ Department of Management of Organizations and Administration, Podolsky State Agrarian Technical University.

E-mail: alladama@mail.ru 
можность сельскохозяйственного производства обеспечить полную занятость и Аостойный уровень жизни сельских жителей вызывает потребность в поиске решения этих проблем с помощью преАпринимательской Аеятельности.

Проблема Аиверсификации, несмотря на повышенное внимание к ней, изучена еще недостаточно. Зарубежные ученые И. Ансофф, К. Боумен, Аж. Гэлбрейт, А. Аэй, П. Арукер, Т. Минтцберг исследовали вопросы стратегии, сбалансирования ассортиментного портфеля, обеспечения финансовой устойчивости. В начале 90-х годов. российские и украинские ученые продолжили изучение этих проблем. Незауряаные Аостижения в этой научной сфере Аолжны А.Н. Аронов, В. А. Гришко, С.М. Ильяшенко, Е.А. Козцовская, И.М. Кублин, В. Моисеев, И. Немченко, А.Н. Петров, Р.Б. Тян и Аругие. Впрочем, несмотря на исследования Аанной проблематики названными авторами, остаются серьезные вопросы теоретического и методологического характера во время формирования Аиверсификационной политики.

В странах с развитой рыночной экономикой уделяется большое внимание вопросам развития преАпринимательства на селе и его вмияния на Аиверсификацию сельской экономики. Весомый вклаА в изучение этих проблем сАелали такие известные отечественные ученые, как С. ГуАзинский, А. Онищенко, М. Орлатый, И. Прокопа, П. Саблук, М. Хвесик, В. Юрчишин, К. Якуба; зарубежные - $А$. Ван Аепоель, Ж. Уилкин, Т. Ауча, Х. Каравемле, М. Кларк, Т. Аонч и много Аругих. ОАнако, не считая на разноплановость и глубину проведенных исследований, эта проблема остается недостаточно изученной и требует Аальнейшего исслеАования.

\section{2. Теоретические аспекты Аиверсификации}

Аиверсификация - это процесс, охватывающий организационные, экономические, правовые изменения на преАприятиях и направлен на повышение эффективности производства, снижение количества банкротств, своевременное реагирование на изменения экономической конъюнктуры рынка Аля обеспечения прибыльности на основе использования рыночных шансов и установцения конкурентных преимуществ, укрепления положения преАприятия в рыночном сегменте (Г ушак 3.M., 2009).

Аиверсификация как общественная форма организации производства может обеспечить ряА преимуществ:

Во-первых, она явцяется важным среАством управления финансовыми рисками.

Во-вторых, Аиверсификация позволяет полнее использовать свои материальные ресурсы, землю и рабочую сику и благодаря этому смягчить сезонность производства, повысить занятость работников, получить Аополнительный АохоА от своевременной и проАуманной отраслевой маневренности, быстрее наращивать объемы производства тех видов продукции, на которые есть спрос и формируется приемлемая цена (Томпсон А.А., ми. СтрикленА А.Аж., 2009).

Аиверсификация может происходить по слеАующим вариантам:

- Первый - когАа диверсификация связана с потребностями потребителей. Она представмяет собой освоение новой Аля преАприятия технологии с целью продолжить обскуживание традиционного рынка. Такой вариант развития диверсификации может осуществцяться или путем покупки уже существующей фирмы с новой технологией, или же созАание нового производства, опираясь на внутренние источники. НереАко, ввеАя продукцию с новой технологией, преАприятие теряло мидерство в отрасли.

- Второй вариант Аиверсификации связан с технологией и заключается в применении традиционной техномогии преАприятия Аля УАовметворения новых потребностей. Пример - распространение эмектроники в машиностроении. Осуществляется мибо путем поглощения (например, автомобильная кампания поглощает эмектронную), или путем внутреннего развития из-за выхода на новые рынки.

- Третий вариант Аиверсификации - переход в область, не связанную с текущим бизнесом преАприятия, к новым технологиям или потребностей рынка. Такую Аиверсификацию называют еще конгломератной Аиверсификацией. Она осуществляется, как правило, путем приобретения фирмы. То есть созАается новый конгломерат, объединяющий преАприятия многих отраслей, не связанных межАу собой технологической цепью. Эти предприятия действуют как самостоятельные и только финансово и административно зависят от главного офиса конгломерата (Костюк Т.А., 2007).

ОАнако Аиверсификация Аеятельности преАприятия не только является инструментом Аля увеличения реамизации услуг, она явмяется инструментом межотрасмевого перераспределения финансовых ресурсов, методом оптимизации структурных преобразований в экономике; позволяет снижать негативные послеАствия финансовых и экономических рисков, повышает аАаптивные качестве субъектов хозяйствования на отечественном рынке; явмяется важнейшей составмяющей и оАновременно одним из главных механизмов процесса реструктуризации и повышения конкурентоспособности компаний; формирует корпоративный класс веАущих менеАжеров, принимающих управленческие решения в условиях кризиса и риска.

\section{3. ВАияние Аиверсификации на развитие сельских территорий}

На современном этапе поА Аиверсификацией Аеятельности преАприятия на сельских территориях понимают в широком смысле распределение капиталов межАу размичными объектами, проникновение в новые отрасли и сферы деятельности, расширение географических границ Аеятельности, расширение ассортимента, номенклатуры продукции преАприятия. Стратегия Аиверсификации заключается в уменьшении риска 
фирмы с помощью распредемения инвестиций и Аругих ресурсов межАу несколькими направлениями деятельности - ПроизвоАством разнородных товаров и преАОставлением размичных услуг.

Современные тенденции развития сельских территорий нашего государства схожи с европейскими и мировыми и происходят в направлении сужения сферы приложения труда. Также Аля Украины характерны остаются несоответствие профессионально-квалифицированной качестве рабочих потребностям работодатемей и рост безработицы (Харчук С. А., 2015).
На национальном и региональном уровнях ЕС паралмельно существует несколько концеПций (подходов), из которых можно четко выделить три концепции развития семьских территорий, а именно:

- концепция, которая идентифицирует сельское развитие с общей модернизацией сельского хозяйства и агропродовольственного компиекса. Эта концепция берет за основу развитие сектора (отраслевая модель); - концепция, которая связывает сельское развитие исключительно с уменьшением разАичий межАу наибомее отсталыми сельскими районами и остальной секто-

Таблица 1

\section{Модели развития сельских территорий}

\begin{tabular}{|c|c|c|c|}
\hline \multirow{2}{*}{ Характеристика } & \multicolumn{3}{|c|}{ Модели развития сельских территорий } \\
\hline & отраслевая & перераспределительная & территориальная \\
\hline Цели политики & $\begin{array}{l}\text { Выравнивание доходов с } \\
\text { Аругими отраслями } \\
\text { Рост масштабов производства } \\
\text { (на уровне преАприятия) } \\
\text { Интенсификация производ- } \\
\text { ства (капитал на единицу } \\
\text { площади / труда) }\end{array}$ & $\begin{array}{l}\text { Компенсация вмияния неблагопри- } \\
\text { ятных природных и социально-эко- } \\
\text { номических факторов } \\
\text { Сокращение размичий межАу } \\
\text { отсталыми семьскими районами и } \\
\text { городскими районами } \\
\text { Аиверсификация доходов сельскохо- } \\
\text { зяйственного преАприятия }\end{array}$ & $\begin{array}{l}\text { Использование внутренних ресурсов } \\
\text { территории } \\
\text { Аиверсификация доходов сельскохозяй- } \\
\text { ственных предприятий } \\
\text { Новые формы сокращения расходов } \\
\text { Распространение форм Аиверсифицирован- } \\
\text { ных видов Аеятельности } \\
\text { Формирование несельскохозяйственных } \\
\text { видов деятельности (промышиенное и } \\
\text { ремесленное производство, услуги и др.) }\end{array}$ \\
\hline $\begin{array}{c}\text { Тип } \\
\text { привимегированной } \\
\text { политики }\end{array}$ & $\begin{array}{l}\text { ПодАержка инвестиций в } \\
\text { развитие преАприятия } \\
\text { Прямая поААержка Аоходов } \\
\text { производителей }\end{array}$ & $\begin{array}{l}\text { Компенсационные выплаты горным } \\
\text { и депрессивным районам } \\
\text { ПодАержка инвестиций в развитие } \\
\text { сельскохозяйственного преАприятия } \\
\text { Аиверсификация источников } \\
\text { Аоходов сельскохозяйственного } \\
\text { преАприятия }\end{array}$ & $\begin{array}{l}\text { ПодАержка Аиверсификации доходов } \\
\text { Политики местного экономического } \\
\text { развития } \\
\text { ПодАержка развития инфраструктуры и } \\
\text { услуг Аля местного насемения } \\
\text { ПодАержка инвестиций в сельскохозяй- } \\
\text { ственное преАприятие }\end{array}$ \\
\hline Роль территорий & $\begin{array}{l}\text { «Контейнер» ресурсов / вло- } \\
\text { жения в сельское хозяйство } \\
\text { Сельский = сельскохозяй- } \\
\text { ственный пространство } \\
\text { Ауализм сельский / городской }\end{array}$ & $\begin{array}{l}\text { Центральная роль слабых сель- } \\
\text { ских территорий (горные районы, } \\
\text { Аепрессивные сельские территории, } \\
\text { неблагоприятные районы) } \\
\text { Внимание критериям определения } \\
\text { «слабые сельские районы» }\end{array}$ & $\begin{array}{l}\text { Внимательное отношение ко всему сель- } \\
\text { ского } \\
\text { Неоднородность сельских районов в регио- } \\
\text { нальном и европейском контексте } \\
\text { Многомерное определение понятия «сель- } \\
\text { ский» } \\
\text { Снижение разрыва между слабыми } \\
\text { сельскими территориями и городскими } \\
\text { районами }\end{array}$ \\
\hline Роль отраслей & $\begin{array}{l}\text { Центральное место сельского } \\
\text { хозяйства и профессиональ- } \\
\text { ного сельскохозяйственного } \\
\text { преАприятия } \\
\text { Интеграция сельского } \\
\text { хозяйства и агробизнеса в } \\
\text { гмобальный контекст }\end{array}$ & $\begin{array}{l}\text { Центральное место сельского } \\
\text { хозяйства } \\
\text { Аругие отрасли как возможность } \\
\text { Аиверсифицированного развития } \\
\text { семьскохозяйственных предприятий }\end{array}$ & $\begin{array}{l}\text { Центральное место сельского хозяйства, } \\
\text { Авигателя процессов сельского развития } \\
\text { (первый вариант модели) } \\
\text { Центральное место Аругих отраслей Аля } \\
\text { Аиверсификации местной экономики (вто- } \\
\text { рой вариант модели) }\end{array}$ \\
\hline $\begin{array}{c}\text { Роль социальных } \\
\text { структур }\end{array}$ & $\begin{array}{l}\text { Центральное место профес- } \\
\text { сиональных организаций, } \\
\text { организаций производителей }\end{array}$ & $\begin{array}{l}\text { Аоминирование организаций произ- } \\
\text { водителей } \\
\text { Большое внимание в отношении } \\
\text { операторов несельскохозяйственных } \\
\text { отраслей }\end{array}$ & $\begin{array}{l}\text { Сельское развитие как процесс с множе- } \\
\text { ством действующих миц } \\
\text { Необходимость форм и механизмов управ- } \\
\text { цения конфмиктами } \\
\text { Центральное место концепции партнерства } \\
\text { Центральное место распространение сетей }\end{array}$ \\
\hline $\begin{array}{c}\text { Роль } \\
\text { институциональных } \\
\text { структур }\end{array}$ & $\begin{array}{l}\text { Концентрация управмения } \\
\text { политикой в руках аАмини- } \\
\text { страции области (региональ- } \\
\text { ной и национальной) }\end{array}$ & $\begin{array}{l}\text { Аоминирующая роль отраслевой } \\
\text { аАминистрации в управлении } \\
\text { направмениями политики } \\
\text { Распространение форм кооперации } \\
\text { и / или интеграции с администра- } \\
\text { цией других отраслей }\end{array}$ & $\begin{array}{l}\text { Создание форм местного и децентрализо- } \\
\text { ванного правительства } \\
\text { Многоуровневое управмение политиками и } \\
\text { направмениями развития }\end{array}$ \\
\hline
\end{tabular}

Источник: (Kolesnikov, 2014) 
рами экономики (концепция сближения, перераспредемительная модель). Это преАполагает развитие, прежАе всего, традиционных отраслей (агротуризм, сельский туризм, переработка сельскохозяйственной продукции в самых хозяйствах и т.п.);

- концепция, которая идентифицирует сельское развитие с развитием сельских районов в целом путем использования всех ресурсов, находящихся на их территории (человеческих, физических, природных, манАшафтных и Ар.), И интеграции межАу всеми компонентами и отраслями на местном уровне. Эта концепция использует возможности территории в самом широком ее понимании (территориальная модель).

Этим трем концепциям соответствуют три разные, хотя и не формализованные модели, которые используются Аля объяснения политики развития сельских территорий (таблица 1).

В мировой практике понятие многофункционального развития сельских территорий тесно связано с увеличением Аоли несельскохозяйственных видов деятельности на семе. Опыт зарубежных стран, особенно экономически развитых, указывает на растущую важность несельскохозяйственных видов деятельности на сельских территориях как альтернативных источников доходов и предпосыиок Аальнейшего социально-экономического развития отдельных местностей. В мире уже в течение нескольких десятилетий происходит активное пропагандирование Аиверсификации видов экономической Аеятельности на сельских территориях, традиционно были только местом ведения сельского хозяйства. БлагоАаря активной деятельности в этом направлении в начале XXI века 30-35\% доходов Аомохозяйств на сельских территориях (в частности, 42\% в Африке, $40 \%$ в Южной Америке и $32 \%$ в Азии) были получены от осуществления несельскохозяйственных видов экономической деятельности (Несельскохозяйственных занятость в сельской местности Украины, 2015).

Украина Аолжна использовать опыт европейских стран, поскольку имеющийся потенциал способен обеспечить развитие сельских территорий, активизировать формирование новых, в том числе несельскохозяйственных видов экономической Аеятельности. Примером Аиверсификации на сельских территориях явцяется сельский туризм. Сельский туризм может стать оАним из крупнейших прибыльных видов бизнеса том, что он является одним из самых дешевых и Аоступных видов туристического отдыха. Украинские села имеют большой потенциал, веАь в каждом регионе отмечается разнообразием мандшафтных комплексов, значительным историко-культурным, этническим и генетическим Аостоянием и именно поэтому рациональное их использование с помощью туристической индустрии следует рассматривать как один из действенных путей преодоления экономических и демографических проблем.

\section{4. Выводы}

Амя успешной реализации стратегии Аиверсификации необходимо активное участие и подАержка органов местного самоуправления.

Во-первых, они могут активно способствовать формированию благоприятной среды Аля развития бизнеса через механизмы регистрации нового бизнеса, перехода прав собственности на землю, управления коммунальной собственностью и земельными ресурсами.

Во-вторых, местные власти могут предоставмять некоторые мьготы новому бизнесу в налогообложении, привлекать необходимые бюджетные средства на поААержку социально значимых видов деятельности.

В-третьих, ведение бизнеса предусматривает получение прибыли. Инвестор Аолжен быть уверен, что политика местных органов власти явцяется стабильной и не помешает ему вернуть все вложенные в бизнес ресурсы. Таким образом, Аеятельность органов местного самоуправления явцяется своеобразной гарантией Амя преАприниматемей, их инвестиции экономически оправданы и они имеют перспективы развития на территории общины. В случае нарушения бизнесом прав жителей общины и неэквивалентности выгоА, которые получает местное сообщество, органы местного самоуправления Аолжны иметь механизмы прекращения Аеятельности таких хозяйствующих субъектов.

Аиверсификация сельской экономики Аолжна стать основным инструментом социально-экономического развития сельской экономики, среАством обеспечения высокоэффективной хозяйственной деятельности за счет: развития мелкого и среАнего преАпринимательства на селе и рост самозанятости сельского населения; расширение сфер приложения труда, рост спроса на квалифицированную рабочую сику, повышение мобильности рабочей силы и созАание новых рабочих мест; обеспечение бесперебойного производственного процесса и сглаживания сезонности сельскохозяйственного производства; обеспечение устойчивых источников Аоходов, умучшение материального благосостояния и уровня жизни сельского населения; рост инвестиционного капитала сельской территории; обеспечение сбалансированности социально-экономического развития. Именно такой поАхоА связан с европейской моделью сельского хозяйства.

\section{References}

Grushak Z.M. (2009). Diversifikatsiya kak strategiya deyatelnosti. Ekonomika, finansyi, pravo, (5): p. 6-9.

KolesnikovV.I. (2014). Mirovoy opyit razvitiya selskih territoriy. Elektronnoe nauchnoe spetsializirovannoe izdanie «Effektivnaya ekonomika», (4). [Electronic resource]. - Retrieved from: http://www.economy.nayka.com.ua/ ?op $=1 \& z=2956$ 
Kostyuk T.A. (2007). Diversifikatsiya kak istochnik sinergiynogo effekta. Formirovanie ryinochnyih otnosheniy v Ukraine, (3): p. 10-13.

Neselskohozyaystvennyih zanyatost v selskoy mestnosti Ukrainyi (2015). Institut ekonomicheskih issledovaniy i politicheskih konsultatsiy. [Electronic resource]. - Retrieved from: http://www.ier.com.ua/files/publications/ Policy_papers/German_advisory_group/2005/U13_ukr.pdf

Tompson A.A., ml. Striklend A.Dzh. (2009). Strategicheskiy menedzhment: kontseptsii i situatsii: Uchebnik dlya vuzov. Per. s 9-go angl. izd. - M. : INFRA-M, 928 p.

Harchuk S. A. (2015). Diversifikatsiya ekonomiki kak instrument sovershenstvovaniya razvitiya selskih territoriy. Vinnitskiy uchebno-nauchnyiy institut ekonomiki. [Electronic resource]. - Retrieved from: http://www.economy-confer.com.ua/full-article/1848/

\section{Артур ИЛьНИЦКИЙ, Алла ЧИКУРОВА \\ ДИВЕРСИФИКАЦИЯ КАК ОДИН ИЗ ИНСТРУМЕНТОВ АНТИКРИЗИСНОЙ СТРАТЕГИИ РАЗВИТИЯ СЕЛЬСКИХ ТЕРРИТОРИЙ НА УКРАИНЕ}

Аннотация. Главной целью этой работы является обоснование проблемы развития сельских территорий в условиях кризисной ситуации и показан один из выходов социально-экономической проблемы развития сельской местности, а именно предложено диверсификация производства и услуг. Поэтому растущая конкуренция на рынке требует поиска новых эффективных путей и методов для обеспечения выживания предприятий на сельских территориях в условиях рыночной среды. Одним из этих методов является внедрение диверсификации. Диверсификацию собственной хозяйственно-финансовой деятельности предприятия различных отраслей на сельских территориях проводят не только в условиях глобализации мировой экономики, связанной с взаимопроникновением технологий и капиталов, но и в кризисных условиях как один из инструментов антикризисной стратегии развития. Эффективность ее осуществления напрямую зависит от своевременной ориентации на виды товаров, работ, услуг, которые пользуются спросом или приближаются к уровню конкурентоспособности. Вопросы стратегии развития предусматривают разработку методики получения, обработки и представления информации, связанной с освоением новых технологий, видов продукции, рынков и других видов и направлений деятельности, а также с выявлением закономерностей по определению мотивации диверсификации как стратегии развития предприятия сельской местности. Методологчческой базой для разработки данной статьи, направленной на комплексное развитие сельских территорий во всей его многомерности и разноаспектности стали основательные научные исследования и активные дискуссии в среде компетентных специалистов и заинтересованных лиц, а также сформированные на их основе решения органов государственной власти и местного самоуправления, ориентированные на развитие производственного потенциала, улучшение качества природной среды и повышение качества человеческого капитала сельских территорий Украины. Результат. Диверсификация экономической деятельности в развитии сельских территорий является адекватным ответом не только на вызовы глобализации мировой экономики, связанной с взаимопроникновением технологий и капиталов, но и в кризисных условиях - один из инструментов антикризисной стратегии развития. Эффективность диверсификации напрямую зависит от своевременной ориентации на виды товаров, работ, услуг, которые пользуются спросом или приближаются к уровню конкурентоспособности. Практическое значение. Таким образом, предложенный нами механизм разработки программы социального развития позволит удовлетворить потребности населения в объектах социальной инфраструктуры, решить проблему территориального размещения этих объектов, разработать конкретные меры по улучшению функционирования социальной инфраструктуры различного назначения и, главное, - найти пути финансирования такихпрограммы, которые позволят преодолеть диспропорции развития областей Украины в целом и районов областей и обеспечить население рабочими местами. Значение/оригинальность. Диверсификация экономики села является ключом к уменьшению значительной зависимости от сельского хозяйства и к развитию новых видов экономической деятельности, создание новых предприятий и привлечения инвестиций. Она также может способствовать повышению уровня занятости и доходов сельского населения, увеличению выпуска продукции с высокой добавленной стоимостью, улучшению качества человеческого капитала и, наконец, помочь повысить развитие сельских территорий. 